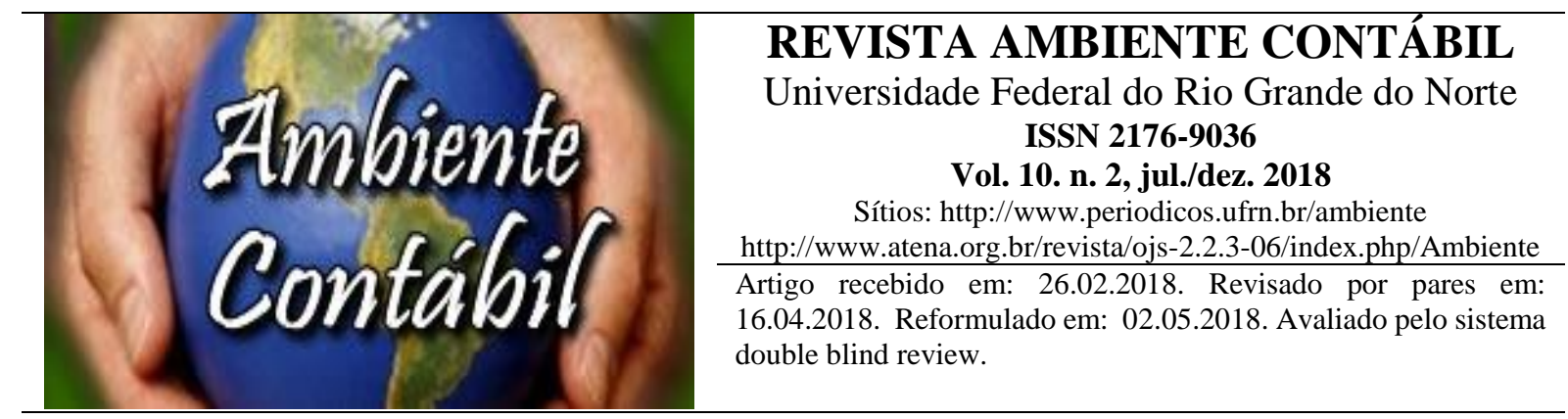

\title{
UMA ANÁLISE SOBRE OS TRIBUTOS DIFERIDOS NO SETOR DE CONSTRUÇÃO CIVIL
}

\section{AN ANALYSIS ON DEFERRED TAXES IN THE CIVIL CONSTRUCTION SECTOR \\ UN ANÁLISIS SOBRE LOS TRIBUTOS DIFERIDOS EN EL SECTOR DE CONSTRUCCIÓN CIVIL}

Autores

Paulo César de Melo Mendes

Doutor em Ciências Contábeis pelo Programa Multi-institucional e Inter-regional em Pós-

Graduação Pela UFPB/UFRN/UnB. Professor Adjunto do Departamento de Ciências Contábeis da Universidade de Brasília- UnB. Endereço: Campus Universitário Darcy Ribeiro, Ed. FACE Bloco A3 sala 82/4 - Brasília - DF - Brasil. Telefone: 556131071432 Identificadores (ID): Lattes: http://lattes.cnpq.br/0880896382546384 E-mail: mendes@unb.br Renan Palhares Torreão Braz
Bacharel em Direito pelo Centro Universitário de Brasília - UniCeub. Bacharel em Ciências
Contábeis pela Universidade de Brasília - UnB. Endereço: SQS 313, Bloco K, Apto. 501 -
CEP 70382-110. Brasília - DF - Brasil. Telefone 55 61 99813-4098.
Identificadores (ID):
Lattes: http://lattes.cnpq.br/8157133773861257
E-mail: palharesrenan@ gmail.com

\section{[Apresentado no $20^{\circ}$ Congresso Brasileiro de Contabilidade]}

\begin{abstract}
RESUMO
O presente artigo teve como objetivo analisar a adequação das práticas contábeis apresentadas pelas entidades do setor de construção civil às recomendações doutrinárias e normativas dos principais órgãos, bem como o impacto, em termos numéricos, dos tributos diferidos. Foram selecionadas 20 empresas construtoras atuantes, classificadas no ranking das maiores construtoras em termos de metros quadrados construídos, noticiadas pela revista Exame. Destamcam-se os itens: a) notas explicativas: b) auditoria externa; c) alíquotas; d) base normativa expressa; e) registro contábil; f) ativo diferido registrado; g) passivo diferido registrado. Como resultado apurou-se um consenso quanto às práticas contábeis empregadas CPC 32. Quanto a relação ativo e passivo, registrou-se o diferimento mínimo, quando existente,
\end{abstract}


de $\mathrm{R} \$ 2.860 .000,00$ (apurado pela construtora Cyrela) representando 0,021\%, e o maior valor de R \$ 24.106.000 (apurado pelo Grupo Via Construtora). Por outro lado, no patamar máximo constatado, o ativo fiscal postergado assume $3,1 \%$ do ativo total registrado de $\mathrm{R} \$$ 754.208.000,00. Os patamares mínimos e máximos, $1,10 \%$ a 30,33\%, do lado passivo, representam uma prorrogação contínua dos impostos e comprometem parte significativa do fluxo de caixa futuro.

Palavras-chave: Construtoras. Imposto Diferido. Imposto de Renda. CPC 32.

\begin{abstract}
The purpose of this article was to analyze the adequacy of the accounting practices presented by the entities of the civil construction sector to the doctrinal and normative recommendations of the main bodies, as well as the numerical impact of deferred taxes. Twenty active construction companies were selected, classified in the ranking of the largest constructors in terms of constructed square meters, reported by Exame magazine. The items are cleared: a) explanatory notes: b) external audit; c) aliquots; d) express normative basis; e) accounting record; f) deferred assets recorded; g) recorded deferred liabilities. As a result, a consensus was reached regarding the accounting practices employed (CPC 32). As regards the asset and liability ratio, a minimum deferral of $\mathrm{R} \$ 2,860,000.00$ (calculated by construction company Cyrela) was recorded, representing $0.021 \%$, and the highest amount of $\mathrm{R} 24,106,000$ (verified by the Via Construtora Group). On the other hand, at the maximum level found, the deferred tax asset assumes $3.1 \%$ of total recorded assets of $\mathrm{R} \$ 754,208,000.00$. The minimum and maximum levels, $1.10 \%$ to $30.33 \%$, on the liabilities side, represent a continuous extension of taxes and jeopardize a significant part of the future cash flow.
\end{abstract}

Keywords: Construction Companies. Deferred Tax. Income Tax. CPC 32.

\title{
RESUMEN
}

El presente artículo tuvo como objetivo analizar la adecuación de las prácticas contables presentadas por las entidades del sector de construcción civil a las recomendaciones doctrinales y normativas de los principales órganos, así como el impacto, en términos numéricos, de los tributos diferidos. Se seleccionaron 20 empresas constructoras actuantes, clasificadas en el ranking de las mayores constructoras en términos de metros cuadrados construidos, reportados por la revista Exame. Se desvelan los ítems: a) notas explicativas: b) auditoría externa; c) alícuotas; d) base normativa expresa; e) registro contable; f) el activo diferido registrado; g) pasivo diferido registrado. En cuanto a la relación activa y pasiva, se registró el diferimiento mínimo, cuando existe, de R \$2.860.000,00 (apurado por la constructora Cyrela) representando el $0,021 \%$, y el mayor valor de R \$24.106.000 (apurado por el Grupo Via Constructora). Por otro lado, en el nivel máximo constatado, el activo fiscal postergado asume el 3,1\% del activo total registrado de $\mathrm{R} \$ 754.208 .000,00$. Los niveles mínimos y máximos, del 1,10\% al 30,33\%, del lado pasivo, representan una prórroga continua de los impuestos y comprometen una parte significativa del flujo de caja futuro.

Palabras clave: Constructoras. Impuesto diferido. Impuesto sobre la renta. CPC 32.

\section{1 - INTRODUÇÃO}

Desde o advento do método das partidas dobradas, até as mais recentes convergências contábeis internacionais, nunca se pôde ignorar na evolução contábil o atendimento às finalidades a que se propõe a ciência, notadamente, ao abastecimento de seus usuários dos dados que procuram para as finalidades que lhes aprouver.

Com efeito, Niyama e Silva (2011) bem ponderam sobre a forma com que os usuários

Revista Ambiente Contábil - ISSN 2176-9036 - UFRN - Natal-RN. v. 10. n. 2, p. 194 - 211, jul./dez. 2018. 
da contabilidade recebem a informação contábil, não em caráter passivo, mas com papel relevante nas escolhas realizadas para efeitos contábeis e pelo próprio contador. Em especial, diante do leque de usuários existentes, destacam essa atuação vinda dos administradores, investidores, auditores e do governo.

Nas próximas linhas, aborda-se uma temática oriunda do conflito aqui tratado, a saber, a contabilização de tributos diferidos. Como se verá, o diferimento de tributos representa forma de alocação de valores entre períodos distintos, o que se dá pela existência de resultados dissonantes entre duas formas de apuração apartadas de lucros, quais sejam, a contábil, para efeitos societários, e a fiscal, para fins tributários.

A solução contábil em meio a este cenário se atrela à observância do Regime da Competência e da Realização, ambos vinculantes em razão da forma contábil fiel à ocorrência de eventos passíveis de registros e da efetiva concretização de tais eventos. Contudo, Hendrix e Van Breda (1999) registram argumentos a favor e contra a alocação dos registros diferidos.

Como se verá, a proposição adiante enfrentada é familiar ao meio acadêmico, certo de que estudos anteriores já abordaram, em outros aspectos, o tema e servirão, com muita riqueza, de embasamento ao atingimento da constatação que se fará ao final (BEAVER; DUKES, 1972).

Dentre elas, estão as discussões sobre gerenciamento de resultados com a utilização de ativos e passivos diferidos, onde empresas aumentam seus resultados, segundo Phillips et al (2004); evidências relevantes para identificação da qualidade e persistência nos lucros, assim como parâmetros para avaliação de empresas, retorno futuro de ações, impactos na classificação de crédito e interpretação do lucro tributável como medida de desempenho das companhias, conforme Martinez e Passamani (2014)

De igual forma, a evolução normativa da matéria, que guarda interesse especial na convergência entre normas internacionais, dará contornos essenciais ao estudo acerca dos tributos sobre o lucro. (APB n 11 , SFAS 96, CPC n 32)

Assim, cabe a seguinte questão: As empresas no setor de construção civil, estão cumprindo as normas de registros do CPC 32- Tributos sobre o Lucro e qual sua amplitude em relação ao ativo e passivo?

Dessa forma o objetivo proposto, é analisar a adequação das práticas contábeis apresentadas pelas entidades às recomendações doutrinárias e normativas, bem como o impacto, em termos numéricos, de tais tributos dentro das entidades.

Busca-se analisar, dentro de um universo das 100 entidades com maior número de metros quadrados construídos em 2014, as 20 melhores colocadas que tornaram acessíveis suas demonstrações financeiras.

Especificamente, pretende-se projetar o menor e o maior valor de diferimento constatado aos montantes totais do agrupamento a que se referem, isto é, ao ativo ou passivo correspondentes, de forma a se identificar a amplitude do envolvimento de um agrupamento bastante influente na economia nacional, os construtores civis, à temática da postergação de tributos.

Por conseqüência, o tema se mostra relevante por aquilatar o grau de envolvimento e dependência do setor de construção civil junto às normas relativas à tributação sobre o lucro, em especial, aos tributos diferidos, consideradas as particularidades deste setor. O setor de construção civil possui características peculiares, tanto do ponto de vista contábil como tributário, contendo execução de serviços a longo prazo, o que contribui para o reconhecimento de tributos diferidos pelas empresas do segmento (PEREIRA; BARBOSA, 2015).

Espera-se evidenciar os critérios de provisionamento dos impostos diferidos e sua relação com as receitas realizadas e seu grau de endividamento.

Ultrapassada a atual fase introdutória, contextualizada a temática e apresentados seus propósitos, este estudo registra: referenciais teóricos que lhe embasam; seu proceder metodológico, com parâmetros de pesquisa e delimitação dos dados envolvidos; resultados e

Revista Ambiente Contábil - ISSN 2176-9036 - UFRN - Natal-RN. v. 10. n. 2, p. 194 - 211, jul./dez. 2018. 
análises frutos do desenvolvimento do projeto; conclusões extraídas a partir da imersão feita no tema, nos dados coletados e nas constatações obtidas.

\section{2 - REFERENCIAL TEÓRICO}

\section{1- EVOLUÇÃO DA ALOCAÇÃO DE TRIBUTOS DE FORMA DIFERIDA ENTRE PERÍODOS}

A matéria relativa aos tributos diferidos, como indicado por Wasserman (2004, p.7) é contextualizada como decorrência da multiplicidade de interesses dos usuários de informações contábeis: os acionistas, voltados ao lucro divulgado para efeitos de distribuição de dividendos; e o fisco, a seu turno, centrado no lucro tributável.

Entende-se que a importância do estudo do tributo diferido como corpo integrante das práticas contábeis decorre da necessidade, crescente, de munir os destinatários das informações contábeis de dados voltados ao futuro (WASSERMAN, 2004, p.133).

Historicamente, resgata-se a preocupação com a alocação de tributos entre períodos como nascida há mais de trinta anos nos Estados Unidos (BIERMAN, 1990, p 42; CHANEY; JETER, 1989, p.6, apud, WASSERMAN, 2004, p.39). Especula-se que, à época, as diferenças temporárias entre lucros contábeis e fiscais não fossem grandes, o que não se manteve constante ao longo dos anos (WASSERMAN, 2004, p.39).

Contudo muitas empresas na década de 80 (GE, Boeing, Lorac Company) divulgaram suas demonstrações com lucros e ainda tinham valores a receber de impostos retidos devido aos diferimentos. Hendriksen, 1999

Já Cunha \& Rodrigues (2004, apud, LOPES, 2014) noticiam que os Estados Unidos da América foram o primeiro país a expedir normativos contábeis relativos a tributos diferidos, o que foi feito mediante publicação do "Accounting for Income Taxes" (ARB n. 23), datado de 1944. A alocação de tributos entre períodos registrou forte evolução nas últimas três décadas em função da intensificação das diferenças entre a contabilidade e as normas tributárias ao longo desse interregno, o que se deu de tal forma que se fez necessária a segregação da apuração de tributos da contabilidade, deflagrando a existência de dois sistemas próprios, cada qual com suas regras (WASSERMAN, 2004, p.133).

O cenário internacional registra duas correntes diferentes a respeito do tema em foco, a anglo-saxônica e a Europeia Continental. A primeira faria prevalecer a substância econômica sobre a forma legal, ao passo que a segunda estaria voltada à satisfação das necessidades dos credores, mediante aplicação literal das regras governamentais, em detrimento da exposição da situação verdadeira e apropriada da entidade (LOPES, 2014, p.1).

Oportunamente, Oliveira et al. (2011, p.26), ressaltam que as divergências entre lucro contábil e lucro fiscal não são exclusividades nossas, dado que ocorrem em boa parte dos países. Elucidam, ainda, que, em plano internacional, este tema tem sido discutido por diversas entidades contábeis, a exemplo do International Accounting Standards Committe (Iasc), o Comitê de Normas Internacionais de Contabilidade, o qual apresentou o Pronunciamento NIC 12, relativo a Impostos sobre a Renda, que também fundamenta o Pronunciamento CPC n. 32, adiante tratado.

No modelo brasileiro, segundo Dantas, Rodrigues, Mendes e Niyama (2014), constatase enorme influência dos preceitos legais, particularmente, de previsões como a da Lei das sociedades anônimas, de $n^{\circ}$ 6.404/76, fato que decorre de nossa tradição jurídica code law, inversa à common Law americana, de forma a se reger até mesmo as funções do contador, este, acostumado a cumprir normas desde o momento de sua formação.

Com efeito, registram-se dissonâncias entre os padrões tributários e os contábeis há certo tempo, como se vê, v.g., pela determinação do Decreto-Lei n. 1598/77 de verificação do

Revista Ambiente Contábil - ISSN 2176-9036 - UFRN - Natal-RN. v. 10. n. 2, p. 194 - 211, jul./dez. 2018. 
lucro tributável em livro apartado, extra contábil, o LALUR - Livro de Apuração do Lucro Real. A existência de dois sistemas contábeis é inequívoca: a contabilidade para efeitos tributários e para efeitos societários (WASSERMAN, 2004, p.11).

Entende-se que as disparidades entre a contabilidade societária e a contabilidade exigida pelos entes governamentais teriam a seguinte tônica: a primeira, fundada em princípios contábeis geralmente aceitos, seria direcionada especialmente ao interesse particular, o que seria, pela ótica do administrador público, prejudicial à coletividade, em alguma medida; a segunda, estritamente vinculada àquilo que é permitido pela legislação e ao interesse público primário, diverge de determinados princípios contábeis ao subordinar-se apenas a leis e normativos (WASSERMAN, 2004, p.8 e 9).

Mesmo dentro das exigências governamentais, inconsistências contábeis são observadas, e.g, entre o Banco Central do Brasil e a Receita Federal. Aquele, voltado à saúde do Sistema Financeiro Nacional, já incentivou a constituição de provisão para créditos de liquidação duvidosa, ao tempo em que esta considerava não dedutível tudo que fosse além das perdas efetivas, após 1997 (WASSERMAN, 2004, p.10).

Nesse cenário, projeta-se que a diferença entre apurações de ambos os sistemas pode se dar de forma permanente ou temporária. Na presença da primeira, existe uma incompatibilidade entre os lucros que não será reparada. A seu turno, as diferenças temporárias podem ser revertidas futuramente, e darão ensejo à alocação de tributos entre períodos. (WASSERMAN, 2004, p.11 e 12).

\section{2 - ATIVO E PASSIVO FISCAIS DIFERIDOS}

Distorções entre valores contábeis e valores fiscais, quando dadas em caráter permanente, não poderão impactar, no futuro, a apuração dos tributos, a exemplo de quando uma dedução não é acompanhada do respectivo comprovante fiscal, ou de multa paga por empresas em função de infração fiscal. Por isso, tais diferenças não são contempladas pela normatização do Pronunciamento CPC n. 32 (OLIVEIRA et al., 2011, p.200).

Por outro vértice, Kronbauer, Souza, Webber e Ott (2012) exemplificam a existência de diferença temporária tributável a partir da determinação de despesa de depreciação considerada na apuração do lucro tributável diferente daquela verificada em resultado contábil, ocasionando uma disparidade entre o valor contábil do ativo e a correspondente base fiscal.

A partir da existência das citadas diferenças temporárias, entende-se como ativo fiscal diferido certas diferenças temporárias, em especial, despesas temporárias contabilmente incorridas e futuramente dedutíveis em lucro tributável. Em termos singelos, essa categoria de ativos traduz a presença de "benefício fiscal futuro a ser auferido quando essas despesas passarem a ser dedutíveis na apuração do lucro tributável” (WASSERMAN, 2004, p.12).

Ao discorrer sobre o ativo fiscal diferido, Wasserman (2004, p. 17) elucida seu contexto histórico. Aponta que a alocação de despesa de tributos almeja, justamente, fazer uma "ponte" entre a contabilidade tributária e a contabilidade financeira, de forma expressa nas demonstrações contábeis. Isto é, o balanço patrimonial e a demonstração do resultado do exercício consignarão desdobramentos tributários futuros de eventos passados ou atuais.

O tributo diferido, quando ativo, traduzirá um benefício fiscal futuro, mais especificamente, o montante do qual se espera reduzir o valor do imposto de renda a pagar posteriormente, caso seu reconhecimento seja dado em função de lucro tributável futuro. Poderá representar, ainda, um direito a restituição, que será condicionado a eventos futuros, se o ativo diferido for registrado a fim de recuperar imposto pago anteriormente (WASSERMAN, 2004, p.17).

No tocante à origem do ativo fiscal diferido, duas são as fontes. A primeira decorre de diferenças temporárias de confronto entre lucro tributável e lucro contábil. Entende-se por

Revista Ambiente Contábil - ISSN 2176-9036 - UFRN - Natal-RN. v. 10. n. 2, p. 194 - 211, jul./dez. 2018. 
diferenças temporárias as deduções feitas contabilmente, porém válidas apenas em momento ulterior para efeitos tributários, uma vez atendidos os pressupostos de dedutibilidade, reversão, dados pela legislação fiscal (WASSERMAN, 2004, p.17).

Com isso, é feita redução da base de cálculo do lucro tributável apurado, seja no passado ou no futuro, através da reversão das diferenças temporárias, de forma a se concretizar o benefício fiscal antes reconhecido pelo ativo diferido (WASSERMAN, 2004, p.17).

A segunda fonte, para Wasserman (2004, p.18), é fruto do prejuízo fiscal, desde que existente regramento legal prevendo sua compensação com lucro tributável. Nessa hipótese, o ativo diferido registrará uma economia tributária em razão da minoração da base de cálculo do tributo por força do abatimento do prejuízo fiscal.

Iudícibus et al. (2010, p. 327 e 328) comentam que o diferimento de tributos do lado ativo decorre do registro de certos custos ou despesas em determinado mês, cuja dedutibilidade para efeitos de IR ou CSLL só será possível em períodos posteriores, a partir de seu pagamento ou comprovação. Com isso, haverá tributo a pagar, porém sua despesa será registrada em períodos seguintes. Na prática, é feita redução da despesa do tributo, em contrapartida à conta do ativo de tributo diferido. $\mathrm{O}$ ativo diferido é consequência da existência de lucro tributável superior ao lucro contábil, a exemplo de quando se têm despesas ou custos deduzidos contabilmente no período corrente, porém serão dedutíveis somente em exercício futuro para finalidades fiscais (WASSERMAN, 2004, p.20).

A seu turno, o passivo diferido virá junto à postergação de receitas tributáveis, bem assim de despesas ou custos que serão deduzidos anteriormente sob a ótica fiscal, em relação à contábil. O mesmo acontece com a reavaliação de ativos com realização adiada para período futuro (WASSERMAN, 2004, p.20).

Como se constata, as diferenças temporárias acabam equiparadas, pela legislação tributária, ao prejuízo fiscal, dado que ambos reduzirão a base de cálculo de tributos (WASSERMAN, 2004, p.25).

A primeira benesse traduz um "pagamento antecipado de uma despesa tributária futura", ao passo que a segunda, na ausência de um valor efetivamente pago, é vista como uma "ativação do imposto a ser economizado quando esse excesso de despesas (pagamentos) sobre as receitas (recebimentos) for passível de utilização, mediante autorização das regras tributárias, para reduzir lucro tributável” (WASSERMAN, 2004, p.26 e 27).

A prática mostra que a compensação futura, representada pelo ativo diferido, nasce a partir de um pagamento de tributo maior do que o "justo", assim entendido aquele que é calculado em princípios contábeis. Entende-se que, quando o lucro tributário é superior ao “justo”, há uma antecipação do imposto (WASSERMAN, 2004, p.28).

Por outro lado, a existência de receitas não realizadas coloca em evidência o passivo fiscal diferido, também ora em estudo.

Isso porque, em relação ao imposto mensurado de acordo com o lucro real, o montante apurado é o apenas o saldo que se deve ao fisco no período em questão. Sob a ótica contábil, dada pelo regime de competência, as despesas de tributo relativas a receitas já registradas contabilmente, porém diferidas para efeitos tributários, devem ser contabilizadas no período em voga. O passivo é certo e tem pagamento realizável apenas em período seguinte. (IUDÍCIBUS, et al., 2010, p.325).

\section{3 - REGIME DE COMPETÊNCIA E REALIZAÇÃO}

Expresso na Deliberação CVM n. 29, de 5 de fevereiro de 1986, o Princípio da Competência estatui que as despesas e receitas de dado período devem ser registradas independentemente da saída dos pagamentos feitos, para o caso das despesas, e da entrada de recursos em caixa, para fins de receita. Com isso, registra-se o ganho (receita), e a despesa

Revista Ambiente Contábil - ISSN 2176-9036 - UFRN - Natal-RN. v. 10. n. 2, p. 194 - 211, jul./dez. 2018. 
incorrida (WASSERMAN, 2004, p.18).

De um lado, em obediência ao regime de competência, é preciso contrapor as receitas realizadas e contabilizadas aos seus correspondentes custos e despesas. Ignorar a prática do diferimento, aqui em estudo, levaria à alocação da despesa tributária a períodos distintos dos correspondentes lucros e receitas contabilizados, daí a importância desta técnica contábil (IUDÍCIBUS et al., 2010, p.329).

A dualidade vinda da Competência e da Realização resgata a questão da prática contábil em contraposição à prática fiscal, tributária, e fundamenta a raiz da necessidade de se diferir tributos.

Com isso, do confronto entre a competência e a realização verifica-se o nascimento de um ativo fiscal diferido se acaso o ajuste necessário consistir em redução de despesa incidente sobre o lucro tributável. A hipótese contrária dá origem ao passivo fiscal diferido, como visto (WASSERMAN, 2004, p.20).

\section{4 - MARCOS LEGAIS: CONTEXTUALIZAÇÃO NORMATIVA DOS TRIBUTOS DIFERIDOS}

$\mathrm{O}$ advento do diferimento de tributos em decorrência de prejuízos fiscais remonta ao Pronunciamento n. 25, de 20/08/98, do IBRACON, Instituto Brasileiro dos Auditores Independentes, o qual foi aprovado pela deliberação da CVM, Comissão de Valores Mobiliários, n. 273/98 (WASSERMAN, 2004, p.77).

Evolutivamente, constata-se que a Instrução CVM n. 371/2002, em especial, pelo seu art. $2^{\circ}$, foi profícua ao estipular as mesmas condições para o reconhecimento do tributo diferido ativo, seja ele decorrente de prejuízos fiscais, seja de diferenças temporárias (WASSERMAN, 2004, p.77).

O reconhecimento do ativo diferido, por conseguinte, estaria condicionado ao atendimento das seguintes condições prescritas pelo art. $2^{\circ}$ da Instrução CVM n. 371/2002: a) apresentar histórico de rentabilidade; b) apresentar expectativa de geração de lucros tributáveis futuros, fundamentada em estudo técnico de viabilidade, que permitam a realização do ativo fiscal diferido em um prazo máximo de dez anos; e c) os lucros futuros referidos no inciso anterior deverão ser trazidos a valor presente com base no prazo total estimado para sua realização.

Anteriormente, o item 040 da Deliberação CVM n. 273/1998 e o art. $7^{\circ}$ da Instrução CVM n. 371/02 traziam determinadas informações a serem publicadas, em demonstrações financeiras e notas explicativas, relativas ao diferimento de tributos (WASSERMAN, 2004, p.78).

As determinações acima apontadas já estavam harmonizadas às práticas internacionais (OLIVEIRA et al., 2011, p.197), de fato, tal forma de apresentação do tributo diferido segue modelo do padrão norte-americano (WASSERMAN, 2004, p.80).

O tema, posteriormente, passou a ser objeto de normatização do Pronunciamento Técnico CPC 32 - Tributos sobre o Lucro, aprovado pela Deliberação CVM n. 599/09, de adoção obrigatória a partir de 1\%01/2010. Segundo a nova previsão, o ativo diferido fiscal seria objeto de reconhecimento após atendidas diversas condições, detalhadas no item 36 do referido Pronunciamento, as quais guardam semelhança com a antiga Deliberação CVM n. 273/98 (item 21). IUDÍCIBUS, et. al, (2010), esclarece essas semelhanças: a) "Existência de valores de diferenças temporárias tributárias que possam ser compensados com saldos de prejuízos ou créditos fiscais, antes de suas prescrições; b) Provável ocorrência de lucros tributáveis antes que os saldos dos prejuízos e créditos fiscais expirem; c) A natureza dos saldos dos prejuízos fiscais não utilizados decorrem de eventos específicos cuja probabilidade de uma nova ocorrência é remota; d) Existência de oportunidades de aproveitamento dos saldos dos prejuízos

Revista Ambiente Contábil - ISSN 2176-9036 - UFRN - Natal-RN. v. 10. n. 2, p. 194 - 211, jul./dez. 2018. 
e créditos fiscais mediante a realização de planejamentos tributários."

Preliminarmente, elucida-se que o objetivo central do CPC 32 foi adequar o registro contábil de tributos que tenham como objeto o lucro, calculados sobre regras fiscais, à contabilidade conforme as PCAB - Práticas Contábeis Adotadas no Brasil (OLIVEIRA et al.2011, p.197).

Em essência, busca-se o nível de certeza, probabilidade e capacidade de dada entidade demonstrar lucros tributáveis futuros que possibilitem a compensação do ativo (IUDÍCIBUS et al., 2010, p.329).

Via de consequência, fica presumido pela CVM que determinada entidade, e.g., não tendo apresentado lucro tributável em três dos últimos cinco anos anteriores, mesmo sem o histórico de rentabilidade a que alude o inciso I do art. $2^{\circ}$ da Instrução n. 371/02, possa apresentar sua justificativa fundamentada para que, em nota explicativa, demonstre ações que levariam a uma geração de lucro tributável (IUDÍCIBUS et al., 2010, p. 330).

Ademais, atribuiu-se ao auditor independente, conforme art. $5^{\circ}$ da referida Instrução, avaliar a correção dos procedimentos feitos para constituição e manutenção do ativo e do passivo fiscal diferido, bem como sobre as bases utilizadas para a atualização desta análise, devendo ser revisada a cada exercício social pela entidade, de sorte a se ajustar o valor do ativo diferido tão logo se altere sua expectativa de realização. Determina-se o arquivamento de toda documentação que tangencie tais análises por ao menos 5 (cinco) anos (IUDÍCIBUS et al., 2010, p.330).

Ainda, o diferimento do pagamento do Imposto de Renda e da Contribuição Social sobre Lucro Líquido decorre do previsto, respectivamente, no art. 409 do RIR/99, da Instrução Normativa SRF n. 21/79 e, por fim, do art. $3^{\circ}$ da Lei n. 8.003/90, este, determinando observância, no tocante às Contribuições, às mesmas normas para diferimento do Imposto de Renda (IUDÍCIBUS et al., 2010, p.296).

Saliente-se que, no tocante às hipóteses de diferimento autorizadas pela legislação, nem todas aquelas aplicáveis ao Imposto de Renda serão compatíveis com a Contribuição Social, apenas aquelas que constem em rol taxativo da legislação pertinente a este tributo (IUDÍCIBUS, et al., 2010, p.327).

A legislação do imposto de renda, espelhada à Contribuição Social, permite a postergação do recolhimento do tributo correspondente ao resultado contabilizado, porém não concretizado financeiramente. Verifica-se, assim, a quantia proporcional registrada como receita, porém não auferida até o fechamento do balanço, a qual poderá ser deduzida do lucro líquido em momento de apuração do lucro real, tributável (IUDÍCIBUS et al., 2010, p.296).

Por derradeiro, no que concerne à alíquota aplicável, observa-se aquela vigente conforme legislação tributária. Eventual alteração na norma legal, em relação à alíquota ou ao cálculo do tributo diferido, deve ser reconhecida assim que se deflagrar sua ocorrência, tido que o tributo diferido ostenta natureza de "crédito" ou de "obrigação" e, como tal, deve ter seu novo valor, após modificado, reconhecido de imediato (IUDÍCIBUS et al., 2010, p.329).

\section{3 - PROCEDIMENTOS METODOLÓGICOS}

Classifica-se a presente investigação como descritiva, em atenção ao que pontuam Raupp e Beuren (2003), ao enquadrarem a pesquisa descritiva como intermediária entre a abordagem exploratória e a explicativa, isto é, "não é tão preliminar como a primeira nem tão aprofundada como a segunda. Nesse contexto, descrever significa identificar, relatar, comparar, entre outros aspectos".

Por conseguinte, a técnica de pesquisa utilizada é de caráter documental e bibliográfica (MEDEIROS, 2006, p.46 e 47), dado que utiliza documentos científicos secundários, com informações analisadas e trabalhadas, notadamente, os balanços patrimoniais, além de aporte

Revista Ambiente Contábil - ISSN 2176-9036 - UFRN - Natal-RN. v. 10. n. 2, p. 194 - 211, jul./dez. 2018. 
bibliográfico voltado, em especial, ao referencial teórico do estudo.

\section{1 - POPULAÇÃO E AMOSTRA}

O setor de construção civil guarda peculiaridades que muito interessam à matéria do diferimento de tributos. É notório que suas atividades rotineiras englobam a assunção de compromissos e pagamentos de longo prazo em contratos privados e públicos, em montas financeiras consideradas expressivas, o que torna inevitável a existência de descompassos entre os regimes de apuração de lucro e, via de consequência, a necessidade de contabilização em conformidade com ambas as formas.

Dessa feita, foram selecionadas as 20 empresas que mais construíram em 2014, conforme noticiado pela revista Exame, em 10/06/2015, com base em consultora especializada, ITC, Inteligência Empresarial da Construção, que divulga ao mercado, para fins de premiação, ranking das "100 construtoras com maior volume de metros quadrados ativos de 2014".

A partir dessa coleta, foi desenvolvida análise minuciosa dos padrões contábeis de tais empresas, na qualidade de referências dentro do setor estudado.

\section{2 - FORMA DE CLASSIFICAÇÃO DE DADOS E APURAÇÃO DE PRÁTICAS ADOTADAS}

Para responder a questão se as empresas estão ou não observando os normativos fiscais e contábeis para formação dos ativos e passivos diferidos e qual sua amplitude em relação ao ativo e passivo, foram verificadas as seguintes variáveis a partir das demonstrações financeiras das entidades, incluídas as notas explicativas: a) auditoria externa envolvida; b) forma de aplicação de alíquota aos tributos diferidos; c) base normativa expressa; d) registro contábil feito; e) valor do ativo diferido registrado; f) valor do passivo diferido registrado; g) tributos envolvidos; h) observações pertinentes.

A coleta de dados foi através da verificação de um chek-list sob a forma de como foi provisionado os valores diferidos e do confronto e análise das notas explicativas. Foram observados os aspectos como: a) alíquota aplicada do imposto de renda e da Contribuição Social sobre o lucro, b) o reconhecimento da depreciação do imobilizado, c) receitas diferidas a longo prazo, e d) o reconhecimento do regime de caixa e competência dos tributos.

Outro aspecto evidenciado foi a forma de controle das empresas explicadas em notas explicativas, onde muitas empresas relatam a existência no final do exercício fiscal e não um controle periódico.

Ao final, foi feito cotejo analítico dos dados, em quadro analítico e em síntese descritiva, ambos complementares.

\section{4 - ANÁLISE DOS RESULTADOS}

A análise adiante trazida será colocada de forma sintética em quadro analítico, de forma a discriminar pontos e detalhamentos específicos dos dados coletados.

\section{1 - MRV}

Conforme elucidado em nota explicativa, a empresa assegura a aplicação da alíquota vigente no período em que o passivo deve ser liquidado ou o ativo realizado, com base na legislação aplicável à época do período relatado. Por conseguinte, a entidade busca aproximar, 
tanto quanto possível, os desdobramentos fiscais esperados pela entidade, ao final de cada relatório, para fins de recuperação ou liquidação de tais ativos e passivos.

Em observância ao CPC 32 e "IAS 12 - Tributos sobre o Lucro", a construtora reconhece, a título de tributos diferidos, a diferença observada entre ativos e passivos para efeitos fiscais e para efeitos de contabilização em demonstrações financeiras, com alíquotas vigentes na data da elaboração das demonstrações.

Aproxima-se a probabilidade da existência de base tributável positiva com que se possam compensar eventuais prejuízos fiscais e utilizar diferenças temporárias. Por isso, findo cada exercício, o saldo do ativo é regulado de forma a demonstrar o montante que se espera recuperar, conforme existência de lucro tributário futuro.

\section{2 - DIRECIONAL}

O Grupo opta por calcular o encargo de imposto de renda e de contribuição social diferido com base na legislação tributária promulgada, ainda que "substancialmente", na data do balanço.

Periodicamente, a entidade avalia alternativas a serem adotadas quando a apuração do Imposto sobre a Renda dá margem para interpretações, a partir da legislação. Nesses casos, são estabelecidas provisões, quando apropriado, com base em valores projetados para pagamento ao fisco.

O Imposto de Renda e Contribuição Social diferidos são contabilizados aplicando-se no passivo as diferenças temporárias entre as bases fiscais, em comparação aos seus valores contábeis correspondentes em demonstrações financeiras. Em especial, destaca-se diferença verificada entre a contabilização pelo regime de caixa, para fins tributários, e pelo regime de competência, para efeitos societários.

A seu turno, os tributos diferidos ativos são reconhecidos na proporção da probabilidade de que lucro tributável futuro se faça disponível e de possível aproveitamento a partir das diferenças temporárias.

\section{3 - CYRELA}

Os tributos diferidos são obtidos pela diferença temporária verificada no fim de cada exercício entre os ativos e passivos reconhecidos nas demonstrações financeiras e as bases fiscais correspondentes decorrentes da apuração do resultado tributável, incluídos saldos de prejuízos fiscais e bases negativas de contribuição social, quando existentes.

Os impostos diferidos passivos derivam de todas as diferenças temporárias tributáveis, ao tempo que os impostos diferidos ativos resultam de todas as diferenças temporárias dedutíveis, caso seja provável a existência de lucro tributável futuro suficiente para que se possa realizar tal dedução.

A revisão do registro de imposto diferido ativo é feita no fim de cada exercício. Quando não mais for provável que os lucros tributáveis futuros possibilitarão a recuperação do ativo, ainda que parcialmente, ajusta-se o saldo do ativo conforme o montante que se espera recuperar.

Utiliza-se a alíquota vigente à época em que se espera que o passivo seja liquidado ou o ativo seja realizado, de acordo com a legislação tributária vigente no fim do exercício, ou com aquela já substancialmente aprovada. Para efeitos de projeção do valor diferido, apura-se a quantia recuperável no momento do fechamento do balanço ao final do exercício.

A entidade destaca, aqui, que as distorções vindas do registro em regime de caixa, pela sistemática fiscal, e em regime de competência, usual para fins societários, ocasionam diferimentos frequentes de tributos. 
Em síntese, os Tributos diferidos da empresa (IRPJ, CSLL, PIS e COFINS) refletem os efeitos fiscais advindos de diferenças temporárias entre os saldos fiscais, que se dá no momento do recolhimento, "conforme o recebimento das vendas de imóveis (Instrução Normativa SRF $n^{\circ}$ 84/79), e a efetiva apropriação do lucro imobiliário, em conformidade com a Resolução CFC $n^{\circ}$ 1.266/09 e Deliberação CVM n ${ }^{\circ}$ 561/08, alterada pela Deliberação CVM nº 624/10 (OCPC 01(R1)”.

\section{4 - BROOKFIELD}

De um lado, os tributos diferidos passivos derivam de diferenças temporárias tributáveis, de outro, os tributos diferidos ativos são reconhecidos a partir de todas as despesas temporárias dedutíveis, bem assim sobre prejuízos fiscais e base negativa de contribuição social, desde que exista probabilidade de a empresa apresentar lucro tributável futuro suficiente para que tais créditos possam ser aproveitados.

Nota-se que a entidade não reconhece diferimento ativo ou passivo de tributos em função de ágio ou de reconhecimento inicial, exceto para combinação de negócios, a partir de ativos e passivos envolvidos em transações que não interfiram no lucro tributável ou contábil.

Para efeitos do diferimento discutido, a entidade aplica a alíquota correspondente ao regime tributário vigente no período em que se espera que o passivo seja liquidado ou o ativo seja realizado.

Ademais, revisa-se o saldo de tributos diferidos ativos, ao menos, no fim de cada exercício. Quando não mais se espera que haja lucro tributável futuro disponível para recuperação de todo o ativo, ou parte, o saldo registrado é adequado àquilo que se espera seja recuperado.

\section{5 - EVEN}

O grupo utiliza as leis tributárias promulgadas nas datas dos balanços. São feitas provisões em casos de interpretações duvidosas para a legislação tributária, notadamente em se tratando de declarações de imposto de renda.

Os tributos diferidos contemplados são o Imposto de Renda e a Contribuição Social sobre Lucro Líquido. São reconhecidos pelo método do passivo sobre diferenças temporárias observadas entre bases fiscais de ativos e passivos e seus valores contábeis em demonstrações financeiras.

Em especial, uma diferença recorrente que é registrada se volta ao critério de apuração de receitas conforme regime fiscal, de caixa, e conforme regime societário, POC.

É feito reconhecimento de tributos diferidos ativos tão somente em casos de provável lucro tributável futuro em disponibilidade, contra o qual os prejuízos fiscais e as diferenças temporárias possam ser confrontados.

\section{6 - ROSSI RESIDENCIAL}

A entidade registra geração de tributos diferidos a partir da existência de diferenças temporárias na data do balanço entre bases fiscais e valores contábeis de ativos e passivos. Os tributos diferidos ativos são reconhecidos a partir da existência provável de lucro futuro tributável hábil à compensação das diferenças temporárias.

Como base de cálculo dos tributos diferidos, utilizou-se a diferença no reconhecimento de lucro na atividade imobiliária para efeitos tributários, em regime de caixa, e para efeitos contábeis, em regime de competência. 


\section{7 - GAFISA}

A realização do imposto de renda diferido se dá a partir da disponibilidade do lucro tributável nos próximos anos para efeitos de compensação do ativo fiscal diferido. Para tanto, são feitas projeções de resultados tendo em conta premissas internas e cenários econômicos futuros que ensejem sua utilização integral ou parcial.

Gera-se imposto de renda diferido a partir de diferenças temporárias à data do balanço ativos e passivos sob a ótica fiscal e sob a ótica contábil. Isto é, as diferenças temporárias e os prejuízos fiscais entre ativos e passivos são confrontados a partir de seus fins contábeis e fiscais.

O reconhecimento é feito na extensão em que os lucros tributáveis futuros possam ser utilizados na compensação do ativo diferido. Em caso de não realização do saldo, é feita uma provisão específica.

\section{8 - MOURA DEBEUX ENGENHARIA}

Os ativos e passivos tributários resultam das diferenças temporárias constatadas entre o lucro contábil, apurado pela forma societária em regime de competência, e o lucro fiscal, dado em regime de caixa.

No tocante à alíquota, utiliza-se aquela que se espera serem aplicadas às diferenças temporárias, uma vez revertidas, tendo como norte as leis decretadas ou substantivamente decretadas até a data de apresentação das demonstrações financeiras.

Para efeitos de Imposto de Renda diferido, a companhia considera instabilidades relacionadas às posturas fiscais adotadas e possíveis consequências financeiras posteriores. Para tanto, é feita avaliação de diversos fatores relacionados ao passivo de Imposto de Renda, inclusive, de interpretações diversas da lei e de experiências passadas.

Caso haja um direito legal de compensar ativos e passivos fiscais correntes, os tributos diferidos são compensados, desde que relacionados a impostos de renda lançados pela mesma autoridade tributária e sobre a mesma entidade tributada.

Um ativo diferido de IRPJ e CSLL é reconhecido na presença de perdas fiscais, créditos fiscais e diferenças temporárias dedutíveis, não utilizados quando é esperado que os lucros seguintes, sujeitos à tributação, estarão disponíveis e contra os quais serão utilizados. Revisamse os ativos de IRPJ e CSLL a cada período, bem como é feita redução conforme decréscimo da probabilidade de sua realização.

O CPC 32 orienta a contabilização da empresa. Em atendimento à Instrução CVM no $371 / 02$, a entidade considera que os créditos tributários diferidos serão realizados ao longo de suas atividades rotineiras.

\section{9 - GRUPO VIA}

O Grupo elucida que os impostos e contribuições diferidos correspondem aos aprovisionamentos sobre as receitas reconhecidas em conformidade com o "progresso físico das obras" e têm seus recolhimentos vinculados ao regime de caixa, no caso de obras públicas.

Incluiu-se, ainda, provisionamentos relativos a tributos sobre o reconhecimento do resultado de incorporação, dado em observância ao custo incorrido, com tributação também vinculada ao regime de caixa. 


\subsection{0 - EZTEC}

O reconhecimento dos tributos diferidos se dá conforme expectativa de recebimento das parcelas previstas nos contratos de compra e venda. O saldo final é apurado pela diferença entre a monta reconhecida a título de saldo a pagar pelo critério societário e o critério fiscal em que a receita é tributada no momento do recebimento.

Com relação a possíveis créditos, a empresa optou por não os registrar, juntamente com sua apuração em regime de lucro real, de forma que é feita apropriação a partir da realização de resultados positivos futuros, por ausência de perspectiva de resultado tributável futuro.

\subsection{1 - TECNISA}

É feito registro da diferença temporal entre a receita pelo critério societário e o critério fiscal, com tributação no momento do recebimento, em regime de caixa.

A base tributária é dada pela alíquota em vigor e o regime tributário adotado. É feita revisão regular dos cálculos dos impostos diferidos passivos a fim de se buscar as reais obrigações à data do encerramento das demonstrações contábeis.

\subsection{2 - WTORRE}

O imposto diferido registrado pela entidade encampa diferenças tributárias ativas e passivas advindas do registro para efeitos de demonstrações financeiras e para efeitos tributários.

O ativo diferido dado a título de Imposto de Renda ou Contribuição Social sobre Lucro Líquido provém da existência de "prejuízos fiscais, créditos fiscais e diferenças temporárias dedutíveis não utilizados", na medida em que seja provável a disponibilidade de lucros tributáveis futuros a serem utilizados. A entidade revisa este dado nas datas de fechamento do balanço, de forma a reduzir seu valor conforme se reduza a probabilidade de realização dos ativos diferidos.

Os impostos diferidos passivos são frutos de ajustes entre parâmetros contábeis distintos entre a contabilidade fiscal e societária. O resultado dessa distinção se dá por momento temporário, certo de que o dever de pagar tributo sobre lucros auferidos em período futuro constitui o passivo fiscal diferido pela entidade. A realização desse passivo acontece junto com a alienação de um ativo, de forma que a diferença temporária tributável, passivo diferido, será revertida e a entidade terá, efetivamente, lucro a ser tributado.

O Grupo enumera os seguintes eventos como ocasionadores de registro contábil de passivo diferido: "valor justo dos imóveis, a forma de apuração dos impostos correntes oriundos de venda, o qual segue o regime de caixa e o valor justo das ações do investimento registrado como instrumento financeiro (nota explicativa $n^{\circ} 7$ )".

O Grupo não procedeu ao reconhecimento de ativos fiscais diferidos pelo fato de as despesas temporárias dedutíveis, os prejuízos fiscais e a base de cálculo negativa acumulada não encontrar prováveis lucros tributários futuros com disponibilidade para uso, à exceção da investida direta WTorre Engenharia e da investida indireta Real AI PIC Securitizadora de Créditos Imobiliários S.A.

\subsection{3 - MÉTODO}

É feito o reconhecimento de diferenças temporárias ao final de cada período a ser relatado, observando-se os saldos de ativos e passivos reconhecidos nas demonstrações contábeis e os parâmetros fiscais correlatos dados para efeitos de apuração do lucro tributável, 
considerados saldos de prejuízos fiscais e bases de cálculo negativas. Utiliza-se a alíquota em vigor.

Elucida-se que os tributos diferidos passivos decorrem de todas as diferenças temporárias tributáveis, ao tempo em que os tributos diferidos ativos são reconhecidos sobre todas as diferenças temporárias dedutíveis, tão somente quando provável a existência de lucro tributável futuro em monta suficiente à utilização de tais diferenças temporárias dedutíveis.

Ao final de cada período de relatório, é feito um estudo de viabilidade técnica para aferir a probabilidade de uso dos tributos diferidos ativos a partir da projeção de obtenção de lucros tributáveis futuros projetados, em comparação ao lucro histórico gerado. Ajusta-se o saldo do ativo de acordo com o montante que se espera seja recuperado.

\subsection{4 - RACIONAL}

A entidade apura adições e exclusões temporárias na determinação do lucro real. Ao final, do confronto entre ambas, incide percentual nominal de $34 \%$ de forma a encontrar o valor total de ativos diferidos. Isto é, faz-se o cotejo entre diferenças temporárias de valores contábeis de ativos e passivos para fins societários e suas correspondências tributáveis.

Utiliza-se a alíquota que se espera aplicar a tais diferenças quando revertidas, em leis promulgadas ou substantivamente decretadas no momento da apuração das demonstrações financeiras.

\subsection{5 - SÁ CAVALCANTE}

A constituição de tributos diferidos passivos foi feita de acordo com o aumento propriedades para investimento dado por avaliação ao valor justo de tais propriedades. Ademais, as obrigações tributárias classificadas como diferidas são advindas de diferenças temporárias do reconhecimento de receita imobiliária pelo regime de competências, em contraposição à legislação tributária vigente.

\subsection{6 - ADOLPHO LINDENBERG}

Os tributos diferidos passivos se dão conforme projeção de realização de receitas, em decorrência de diferenças entre o reconhecimento pela forma societária e pelo critério fiscal, quando tributada a receita mediante seu recebimento efetivo.

O passivo não circulante é integrado por impostos com recolhimento diferido a realizar no exercício seguinte em diante.Os impostos e contribuições diferidos se baseiam nas receitas apropriadas ao resultado dos exercícios, porém não realizadas financeiramente. Sabendo que o recolhimento será efetuado à medida dos respectivos recebimentos, em conformidade com as regras fiscais obedecidas pelo Grupo.

Segundo a entidade, é de ver que as diferenças temporárias dedutíveis, os prejuízos fiscais do imposto de renda e a base de cálculo negativa de contribuição social acumulados não prescrevem, conforme legislação tributária vigente.

\subsection{9 - LORENGE}

A entidade apura diferenças temporárias entre o regime de caixa e o regime de competência contábil. Os tributos envolvidos no diferimento em estudo são: Imposto de Renda, Contribuição Social sobre Lucro Líquido, PIS e COFINS. 
Com isso, o grupo procede à revisão do valor do ativo registrado de forma a adequá-lo à expectativa futura projetada. Utiliza-se a alíquota correspondente ao período em que se espera que o passivo seja liquidado ou o ativo realizado.

\subsection{0 - GRUPO PACAEMBU}

A parcela passiva é reconhecida a partir de diferenças tributáveis, enquanto que a parcela ativa, de diferenças dedutíveis, se provável a existência de lucro tributável futuro suficiente.

\subsection{2 - SÍNTESE ANALÍTICA}

A cargo de ativos diferidos, somados os grupos circulante e não circulante, registra-se o diferimento mínimo, quando existente, de $\mathrm{R} \$ 2.860 .000,00$ (apurado pela construtora Cyrela) até o máximo de $\mathrm{R} \$ 24.106 .000$ (apurado pelo Grupo Via Construtora).

No patamar mínimo observado, quando constatado, tem-se que o ativo fiscal diferido representa $0,021 \%$ do total ativo apresentado pela construtora Cyrela no exercício findo em 31/12/2014, qual seja, a monta de $\mathrm{R} \$ 13.420 .612 .000,00$. Por outro lado, no patamar máximo constatado, o ativo fiscal postergado assume 3,1\% do ativo total registrado pelo Grupo Via em 2014, qual o de $\mathrm{R} \$ 754.208 .000,00$.

A análise do passivo diferido, quando verificado, somados os grupos circulante e não circulante, consigna, em menor valor, o registro de $\mathrm{R} \$ 551.171,00$ feito pelo Grupo Pacaembu, e em maior valor, o registro de $\mathrm{R} \$ 716.632 .705,00$, apurado pela Construtora Sá Cavalcante.

Ante esses dados, sabe-se que o passivo fiscal diferido representa $1,1 \%$ do passivo total apresentado pelo Grupo Pacaembu, de R \$ 47.446.614,00. Já em patamar máximo, o diferimento de tributos integrou 30,33\% dos $\mathrm{R} \$ 2.362 .337 .137,00$ registrados pela Construtora Sá Cavalcante.

Vale dizer, quando existentes tais passivos, o comprometimento com endividamento dos recursos das entidades que registraram valores mínimos e máximos de passivos diferidos é elástico e marca amplitude de $1,1 \%$ a 30,33\%, este último, apontando um financiamento total da entidade de quase 1/3 (um terço) em tributos diferidos, ou melhor, receitas até então não realizáveis sob a ótica tributária.

\section{5 - CONCLUSÃO}

A pesquisa teve como escopo a investigação da prática do diferimento de tributos dentro do setor de construção civil. Dentro dessa delimitação, foi feita coleta de referencial teórico com base em doutrina abalizada e em nomes relevantes no âmbito da contabilidade nacional.

É de fundamental importância que os esforços legislativos e científicos sejam homenageados e acompanhados pelas práticas diuturnas dos operadores da contabilidade, mormente pelos contadores, auditores e usuários.

O setor de construção civil, como é de conhecimento amplo, opera com contratos privados e públicos, em compromissos de longo prazo e assumindo responsabilidades financeiras em montas expressivas. Daí que a discussão relativa às disparidades entre métodos de apuração de lucro, contábil e fiscal, ganham maior magnitude e relevância.

As empresas foram selecionadas conforme: a) ordem de classificação crescente da melhor colocada à pior e; b) disponibilização de demonstrações financeiras, com notas explicativas, via CVM, BM\&FBOVESPA ou no endereço eletrônico da entidade. A análise foi feita de forma individualizada e pormenorizada, conforme item anterior e quadro sintético apresentado.

Em primeiro plano, registra-se a convergência verificada entre os procedimentos 
contábeis assumidos por tais entidades, o que chancela, de modo geral, a atuação dos contadores envolvidos e das auditorias independentes contratadas.

No tocante ao registro contábil constata-se um consenso entre as amostras em alinharse ao que dispõe o CPC 32. Com isso, dá-se atenção às diferenças temporárias tributáveis e dedutíveis advindas da apuração do lucro das entidades pela via fiscal, tributária, em confronto com seu valor correspondente em regime contábil, de competência, de finalidade societária.

Adiante, verificou-se a correta aplicação pelas empresas da alíquota vigente à época do fechamento do balanço, ressalvadas aquelas que indicam adoção de alíquotas "substancialmente" aprovadas, que sugere conflito com a premissa da existência de apenas uma legislação aprovada, vigente, até que outra venha a revogá-la.

Os patamares mínimos e máximos, quando constatada a prática do diferimento superior a zero, registram patamares entre $0,021 \%$ e $3,10 \%$, do lado ativo, e $1,10 \%$ a $30,33 \%$, do lado passivo.

Com isso, fica evidenciada a abrangência da contabilidade em estudo ao usuário da informação, consignada a magnitude do diferimento de tributos, sobretudo passivos, ou seja, a predominância de receitas não realizadas, para fins de apuração fiscal, nos livros contábeis das construtoras estudadas. Apura-se assim, uma preocupação referente aos passivos fiscais diferidos nessas empresas comprometendo 30,33\% das fontes de recursos com impostos que podem afetar o fluxo de caixa futuros. Porém, a vantagem presumida alocação de impostos reside em permitir uma vinculação melhor dos pagamentos aos dados correspondentes de lucros antes de imposto, gerando assim uma predição melhor do lucro liquido futuro divulgado e dos fluxos de caixa. Ofertando assim, melhor as informações aos usuários.

No setor investigado, demonstra uma transferência significativa em alguns casos, de um benefício fiscal no exercício corrente, que não é realizado senão em algum exercício futuro.

O trabalho demonstra que as empresas estão sim, cumprindo a legislação especifica de mensuração e reconhecimento editadas pelo CPC-32 e Deliberação CVM no 599/2009. Quanto a sua amplitude demonstra uma preocupação em receitas diferidas e passivos diferidos comprometendo 30,33\% das fontes de recursos, acusando problema de caixa e de insolvência.

Por fim, reafirma-se o setor de construção civil como destinatário direto de regulamentações especiais voltadas à Tributação sobre o Lucro, evidentemente que não em caráter exclusivo, mas como agrupamento sensível à regulamentação, que pode ser afetado, em magnitude máxima, em praticamente $1 / 3$ (um terço) de seus valores totais.

\section{REFERÊNCIAS}

BEAVER, William F., DUKES, Roland E. Interperiod Tax Allocation: earnings expectations and the behavior of security prices. The Accounting Review, p. 320-322, Apr. 1972;

BRASIL. Comissão de Valores Mobiliários. Aprova o pronunciamento do IBRACON sobre a Contabilização do Imposto de Renda e da Contribuição Social. Deliberação CVM n ${ }^{\circ} 273$, de 20.08.1998.

BRASIL. Comissão de Valores Mobiliários. Aprova o pronunciamento do IBRACON sobre a Contabilização do Imposto de Renda e da Contribuição Social. Deliberação CVM nº 273, de 20.08.1998.

BRASIL. Comissão de Valores Mobiliários. Dispõe sobre o registro contábil do ativo fiscal diferido decorrente de diferenças temporárias e de prejuízos fiscais e base negativa de contribuição social. Instrução CVM n ${ }^{\circ}$ 371, de 27.06.2002.

Revista Ambiente Contábil - ISSN 2176-9036 - UFRN - Natal-RN. v. 10. n. 2, p. 194 - 211, jul./dez. 2018. 
BRASIL. Conselho Federal de Contabilidade. Aprova a NBC T 19.2 0 Tributos sobre os lucros. Resolução CFC nº 998, de 21 de maio de 2004.

BRASIL. Secretaria da Receita Federal. Dispõe sobre o regulamento do imposto de renda. RIR/99. Disponível em: <http://www.planalto.gov.br/ccivil_03/decreto/d3000.htm>. Acesso em 06 nov. 2015.

CPC - COMITÊ DE PRONUNCIAMENTOS CONTÁBEIS. Pronunciamento de n. 32: Tributos sobre o Lucro. Disponível em: http://www.cpc.org.br. Acesso em: 18 out. 2015.

DANTAS, José Alves; RODRIGUES, Fernanda Fernandes; MENDES, Paulo César de Melo; NIYAMA, Jorge Katsumi. Normatização da contabilidade: princípio versus regras. In: NIYAMA, Jorge Katsumi (Org.). Teoria Avançada da Contabilidade. São Paulo: Atlas, 2014. p. 67-92.

FINANCIAL ACCOUNTING STANDARDS BOARD. Discussion memorandum acconting for income taxes. Stamford, Conn. FASB, 1983

HENDRIKSEN, Eldon S., VAN BREDA, Michael F. Teoria da Contabilidade. Ed. Atlas. 1999;

IBRACON - INSTITUTO DOS AUDITORES INDEPENDENTES DO BRASIL. Contabilização do Imposto de Renda e da contribuição social. NPC IBRACON 25/98. Disponível em: <http://www.ibracon.com.br>. Acesso em: 15 nov. 2015.

IUDÍCIBUS, Sergio; MARTINS, Eliseu; GELBCKE, Ernesto R.; SANTOS, Ariovaldo dos. Manual de Contabilidade societária: aplicável a todas as sociedades. São Paulo: Atlas, 2010.

KRONBAUER, Clóvis Antônio; SOUZA, Marcos Antônio; WEBBER, Fabiano Lima; OTT, Ernani. Impacto do Reconhecimento de Ativos Fiscais Diferidos na Estrutura Financeira e no Desempenho Econômico de Empresas Brasileiras. Revista Contemporânea de Contabilidade. UFSC, Florianópolis, v.9, n.17, p.39-60, jan./jun., 2012.

LOPES, Magui dos Anjos. Os Impostos Diferidos no Balanço: Estudo de Caso. Dissertação (Mestrado em Contabilidade e Finanças), Instituto Politécnico de Bragança - IPB/APNOR, 2014.

MARTINEZ, A. Lopo; PASSAMANI, R.Rovetta. BOOK-TAX DIFFERENCES E SUA RELEVÂNCIA INFORMACIONAL NO MERCADO DE CAPITAIS NO BRASIL. Revista de Gestão, Finanças e Contabilidade, ISSN 2238-5320, UNEB, Salvador, v. 4, n. 2, p. 20-37, maio./ago., 2014.

MEDEIROS, João Bosco. Redação Científica: a prática de fichamentos, resumos, resenhas. 8. ed. São Paulo: Atlas, 2006. 
NIYAMA, Jorge Katsumi; SILVA, César Augusto Tibúrcio. Teoria da Contabilidade. 2. ed. São Paulo: Atlas, 2011

OLIVEIRA, Luís Martins de; CHIEREGATO, Renato; JUNIOR, José Hernandez Perez; GOMES, Marliete Bezerra. Manual de Contabilidade Tributária: Textos e testes com as respostas. 10. ed. São Paulo: Atlas, 2011.

PEREIRA, T. R. Lula, BARBOSA, M. Bezerra; Fatores Determinantes na evidenciação de impostos difereidos pelas empresas do setor de construção civil listadas na BM\&FBovesta. RMC, Revista Mineira de Contabilidade, v. 16, n. 2, art. 4, p. 41-50, maio/ago. 2015; Disponível on-line em http://revista.crcmg.org.br/index.php?journal=rmc. Acesso em 20/03/2017

PHILLIPS, John D. et al. Decomposing changes in deferred tax assets and liabilities to isolate earnings management activities. Journal of the American Taxation Association, v. 26, n. s1, p. 43-66, 2004

RAUPP, F. M.; BEUREN, I. M. Metodologia da pesquisa científica aplicável às ciências sociais. In: BEUREN, I. M. Como elaborar trabalhos monográficos em contabilidade. São Paulo: Atlas, 2003. p. 76 - 97.

RODRIGUES, Jomar Miranda. Qualidade da Informação Contábil. In: NIYAMA, Jorge Katsumi (Org.). Teoria Avançada da Contabilidade. São Paulo: Atlas, 2014. p. 183-202.

SANTOS, José Renato dos. Ativos Fiscais Diferidos. Uma proposta de mensuração e registro a valor presente. Monografia (Especialização em Controladoria), Universidade de Brasília - FACE/UNB, 2005.

WASSERMAN, Claudio. O ativo fiscal diferido no sistema financeiro nacional: análise e proposta de contabilização. Dissertação (Mestrado Ciências Contábeis), Universidade de São Paulo - FEA/USP, 2004. 